\title{
Identifying Molecular Genetic Markers Associated with Seedlessness in Grape
}

\author{
M.J. Striem, G. Ben-Hayyim, and P. Spiegel-Roy ${ }^{1}$ \\ Department of Fruit Tree Breeding and Genetics, Institute of Horticulture, Volcani Center, ARO. Bet \\ Dagan 50-250, Israel
}

Additional index words. preselection, breeding, stenospermocarpy, random amplified polymorphic DNA, PCR

\begin{abstract}
Excluding seeded offspring at an early stage could be of great value to the breeder concerned with the development of seedless grapes (Vitis vinifera L.). We used the random amplified polymorphic DNA (RAPD) technique to identify molecular genetic markers, analyzing 82 individuals of a progeny resulting from a cross between 'Early Muscat' (seeded) and 'Flame Seedless'. Seven variables representing the traits of seedlessness were analyzed: mean fresh weight of one seed, total fresh weight of seeds per berry, perception of seed content, seed size categories evaluated visually, degree of hardness of the seed coat, degree of development of the endosperm, and degree of development of the embryo. Among 16010 mer primers, 110 gave distinct band patterns. Twelve markers yielded significant correlations with several subtraits of seedlessness, mainly with the mean fresh weight of one seed and the total fresh weight of seeds per berry. Multiple linear regression analysis resulted in high coefficients, such as $\boldsymbol{R}=\mathbf{0 . 7 7 9}$ for fresh weight of seeds per berry, when the seven markers were included as independent variables in the model. Most of the seeded individuals, about $44 \%$ of the progeny, could be excluded using a two-step process of marker assisted selection.
\end{abstract}

In breeding table grapes, seedlessness is considered a trait of increasing importance to the consumer (Ledbetter and Ramming, 1989). Stenospermocarpic seedlessness in grapes has been discussed in detail since Pearson (1932), Stout (1936) and lately by Ramming et al. (1990), Spiegel-Roy et al. (1990a, 1990b), and Ledbetter and Burgos (1994). Aborted seeds in grapes after fertilization were termed stenospermic (Stout, 1936), and this term was applied to table grapes that were neither parthenocarpic nor seeded. A whole range of sizes of seeds and seed traces is found in progenies from crosses between seeded and seedless cultivars, as well as in crosses between two seedless cultivars. Clear classification of seeded vs. seedless individuals is influenced and biased by several factors. Perceptibility of seed traces may be affected by factors such as the firmness and crispness of the berry flesh (Ledbetter and Shonnard, 1991), the degree of development of the seed, its size and the sclerification of integuments (Ledbetter and Ramming, 1989). On the whole, organoleptic determination cannot be considered a sufficiently valid classification for the degree of seed development.

The need to divide grape progenies resulting from such crosses into seeded and seedless offspring led investigators to look for parameters correlated to the seed content of the berries (Perl et al., 1989). The continuous nature of the parameters used for quantifying the seed content of grape berries (e.g., fresh weight of seeds per berry) led to the need to devise a differentiating tool: $25 \mathrm{mg}$ per aborted seed was used as threshold for seedlessness by Ramming et al. (1990). Our early investigations of this trait resulted in the identification and definition of seven traits related to seedlessness (Striem et al., 1992).

Numerous theories for the inheritance of the stenospermocarpic character have been proposed, analyzing the seeded versus seed-

\footnotetext{
Received for publication 16 Oct. 1995. Accepted for publication 20 Feb. 1996. This research was supported by grant no. US 1888-90 from BARD, the United StatesIsrael Binational Agricultural Research \& Development Fund. We thank Bruce I. Reisch for critical reading of the manuscript, and his valuable suggestions. The cost of publishing this paper was defrayed in part by the payment of page charges. Under postal regulations, this paper therefore must be hereby marked advertisement solely to indicate this fact.

'To whom reprint requests should be addressed.
}

less ratio in progenies. No wholly adequate inheritance scheme, taking into account the variable degrees of development of the seed traces, has yet been proposed. Although few genetic factors are assumed to be involved, it is hard to overlook the quantitative nature of seed development and its response to environmental effects (Kender and Remaily, 1970; Sandhu et al., 1984). We have noted that perceptibility of seed traces is not necessarily correlated to the size of the seed, but rather to the hardness of the seedcoat (Striem et al., 1992). Furthermore, in progenies of crosses between seeded and seedless cultivars, we have noticed several levels of hardness of the seedcoats occurring with different degrees of development of the endosperm. (These observations were considered also in the present study). The degrees of development of the seed components (i.e., seedcoat, endosperm and, possibly, embryo) were therefore evaluated as separate traits, rather than categorizing vines as either seeded or seedless.

The use of multi-loci DNA probes in order to uncover polymorphism between grape cultivars has been demonstrated (Striem et al., 1990). The genetic assay to detect nucleotide sequence polymorphism by polymerase chain reaction (PCR) procedures has been used in grapes. It was mainly used in cultivar identification (Büscher et al., 1993; Gogorcena et al., 1993; Jean-Jaques et al., 1993). We have reported preliminary results on the possibility to use PCR procedures in breeding for seedlessness (Striem et al., 1994). This approach contributed to the identification of several molecular markers correlating with the seedless character in stenospermocarpic grapes. Such markers could be useful as tools for preselection of seedless offspring by excluding the seeded seedlings prior to fruiting as suggested by Gray and Meredith (1992).

The objective of the present investigation was to develop markers associated with seedlessness traits, and to demonstrate their use for marker assisted selection.

\section{Materials and Methods}

Plant material. Progeny from a cross between 'Early Muscat' (E) and 'Flame Seedless' (F) was chosen for the analysis. This progeny was previously analyzed for the seed components of the stenospermocarpic seedlessness trait (Striem et al., 1992). Seven 
Table 1. Marker identification, primer sequence, and parental phenotype of the 12 markers discussed.

\begin{tabular}{|c|c|c|c|c|}
\hline \multirow[b]{2}{*}{ Marker } & Primer sequence & \multirow{2}{*}{$\begin{array}{c}\text { Band size } \\
\text { (bp) }\end{array}$} & \multicolumn{2}{|c|}{ Parental phenotype $^{z}$} \\
\hline & $5^{\prime} \longrightarrow 3^{\prime}$ & & Early Muscat & Flame Seedless \\
\hline 27.4 .2 & TTCCCCCGCT & 700 & 1 & 1 \\
\hline 27.6 .1 & TTCCCCCGCT & 500 & 1 & 0 \\
\hline 33.7 & TCCGCTCTGG & 400 & 0 & 1 \\
\hline 39.5 & CACCAGGTGA & 900 & 0 & 1 \\
\hline 40.9 & ССССАТТССC & 520 & 1 & 1 \\
\hline 46.1 .1 & CTGAGACGGA & 2200 & 1 & 1 \\
\hline 51.5 & ACGACCGACA & 900 & 0 & 1 \\
\hline 60.1 .3 & CTCCATGGGG & 480 & 0 & 1 \\
\hline 62.4 & TGCCCGTCGT & 1350 & 1 & 0 \\
\hline 87.8 & CGGCCCACGT & 700 & 1 & 0 \\
\hline 90.2 & GGGATTCGAC & 1300 & 1 & 0 \\
\hline 90.7 & GGGATTCGAC & 600 & 1 & 0 \\
\hline
\end{tabular}

${ }^{\mathrm{z}} 1=$ Band present; 0 = band absent.

seed traits related to seedlessness were defined: mean fresh weight per seed (mg), total seed fresh weight per berry $(\mathrm{mg})$, seed contents evaluated by perceptibility (Spiegel-Roy, 1979), visual evaluation of four seed size categories, degree of hardness of the seedcoat (1 $=$ soft to $3=$ hard), and degree of development of the endosperm and the embryo ( $1=$ partially developed to 3 = fully developed).

DNA was extracted from young grape leaves following the procedure given by Lodhi et al. (1994). Eighty-two individuals were included in the analysis (39 seedless, and 43 seeded, differentiated visually and by organoleptic perceptibility)

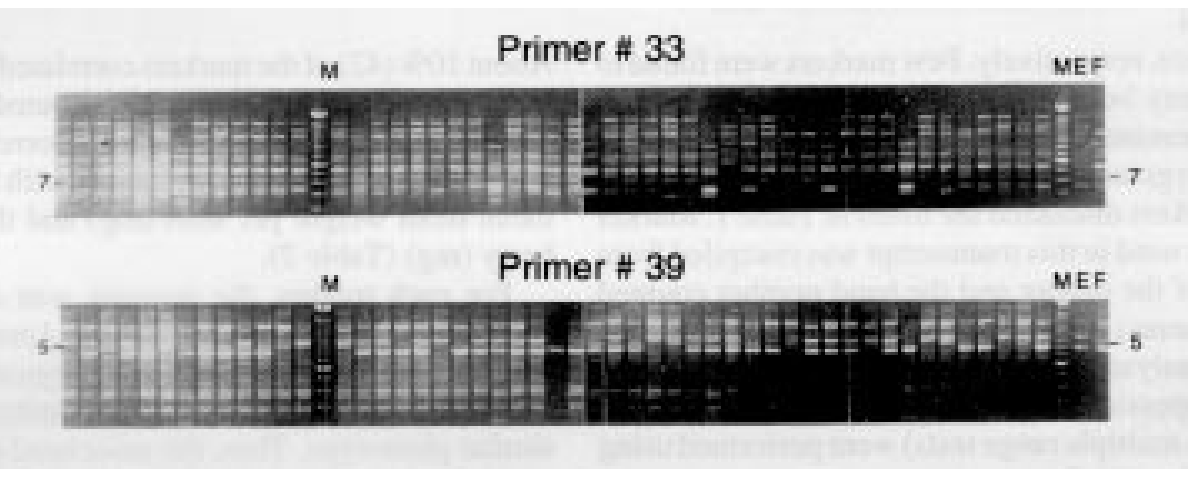

Fig. 1. Electrophoretic separation of RAPD amplification products, using primers 33 and 39. Lanes 1-58: different individuals of the progeny from the cross of 'Early Muscat' (E) with 'Flame Seedless' (F). Marker (M): 100-bp DNA ladder.
Development of molecular markers. Using the RAPD technique for producing molecular genetic markers, more than 160 10 mer primers (Operon kits A,B,C,E,F,G,H,J and other primers) were tested.

Conditions for amplification. The PCR mixture contained 10to 20-ng template DNA in a $25-\mu \mathrm{L}$ reaction volume with $2.5 \mu \mathrm{L} 10 \times$ buffer (Promega Corp., Madison Wis.), 2.0 $\mathrm{mm} \mathrm{MgCl}_{2}, 100 \mu \mathrm{M}$ each dNTP and 1 unit Taq polymerase (Promega), and 0.2 $\mu \mathrm{M}$ primer, covered with a drop of mineral oil. Amplification was performed in a MJ-PTC-60 (MJ re-

Table 2. Correlation coefficients and significance between subtraits of seedlessness and the most significant randomly amplified polymorphic DNA markers, in an 'Early Muscat' x 'Flame Seedless' progeny.

\begin{tabular}{|c|c|c|c|c|c|c|c|}
\hline \multirow[b]{5}{*}{ Marker } & \multicolumn{7}{|c|}{ Morphological trait } \\
\hline & \multicolumn{2}{|c|}{ Fresh wt } & & & & & \\
\hline & \multirow{3}{*}{$\begin{array}{l}\text { Mean one } \\
\text { trace } \\
(\mathrm{mg})\end{array}$} & \multirow{3}{*}{$\begin{array}{c}\text { All traces/ } \\
\text { berry } \\
(\mathrm{mg})\end{array}$} & \multicolumn{2}{|c|}{ Seed size } & \multirow{2}{*}{\multicolumn{3}{|c|}{$\begin{array}{l}\text { Developmental } \\
\text { degree }\end{array}$}} \\
\hline & & & By & & & & \\
\hline & & & perceptibility & Visually & Seedcoat & Endosperm & Embryo \\
\hline 27.4 .2 & $-0.48^{* * *}$ & $-0.42^{* *}$ & NS & NS & $-0.37^{*}$ & NS & $-0.27^{*}$ \\
\hline 27.6 .1 & $-0.32^{*}$ & $-0.34^{*}$ & NS & NS & NS & NS & NS \\
\hline 33.7 & $-0.47^{* *}$ & $-0.52^{* *}$ & $0.38^{* * *}$ & $-0.32^{*}$ & $-0.42^{* *}$ & $-0.34^{*}$ & $-0.33^{*}$ \\
\hline 39.5 & $-0.41^{* *}$ & $-0.44^{* *}$ & $0.29^{*}$ & $-0.41^{* *}$ & NS & $-0.38^{*}$ & $-0.40^{*}$ \\
\hline 40.9 & NS & $0.28^{*}$ & $-0.36^{*}$ & NS & NS & NS & $0.27^{*}$ \\
\hline 46.1 .1 & $-0.35^{*}$ & NS & NS & $-0.30^{*}$ & NS & NS & $-0.30^{*}$ \\
\hline 51.5 & $-0.40^{* *}$ & $-0.36^{*}$ & $0.27^{*}$ & $-0.40^{* *}$ & $-0.33^{*}$ & NS & $-0.30^{*}$ \\
\hline 60.1 .3 & NS & $-0.33^{*}$ & NS & NS & $-0.37^{*}$ & NS & NS \\
\hline 62.4 & $0.28^{*}$ & $0.26^{*}$ & NS & $0.29^{*}$ & $0.40^{* *}$ & NS & $0.30^{*}$ \\
\hline 87.8 & $0.38^{* *}$ & $0.38^{* *}$ & $-0.32^{*}$ & $0.32^{*}$ & NS & NS & NS \\
\hline 90.2 & $0.36^{*}$ & $0.31^{*}$ & NS & NS & $0.29^{*}$ & $0.35^{*}$ & $0.30^{*}$ \\
\hline 90.7 & $-0.48^{\text {*** }}$ & $-0.47^{* *}$ & $0.27^{*}$ & $-0.29^{*}$ & $-0.35^{*}$ & $-0.27^{*}$ & $-0.34^{*}$ \\
\hline
\end{tabular}

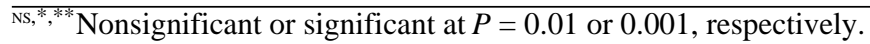


search, Watertown, Mass.) thermal cycler for 37 cycles, after initial denaturation for $30 \mathrm{~s}$ at $95{ }^{\circ} \mathrm{C}$, one cycle of $1 \mathrm{~min}$ at 35 ${ }^{\circ} \mathrm{C}$, and $2 \mathrm{~min}$ at 72 ${ }^{\circ} \mathrm{C}$, was followed by 36 cycles consisting of $30 \mathrm{~s}$ at $94^{\circ} \mathrm{C}, 1 \mathrm{~min}$ at $35^{\circ} \mathrm{C}$, and $1 \mathrm{~min}$ $45 \mathrm{~s}$ at $72^{\circ} \mathrm{C}$. Amplification products were resolved by electrophoresis at $10 \mathrm{~V} / \mathrm{cm}$ for $3 \mathrm{~h}$ in a $2 \% \mathrm{Nu}-$ Sieve agarose gel, in TAE buffer. Gels were stained with ethidium bromide and visualized on UV light. Results were recorded from Polaroid pictures manually. Data on distinct, segregating bands were analyzed as

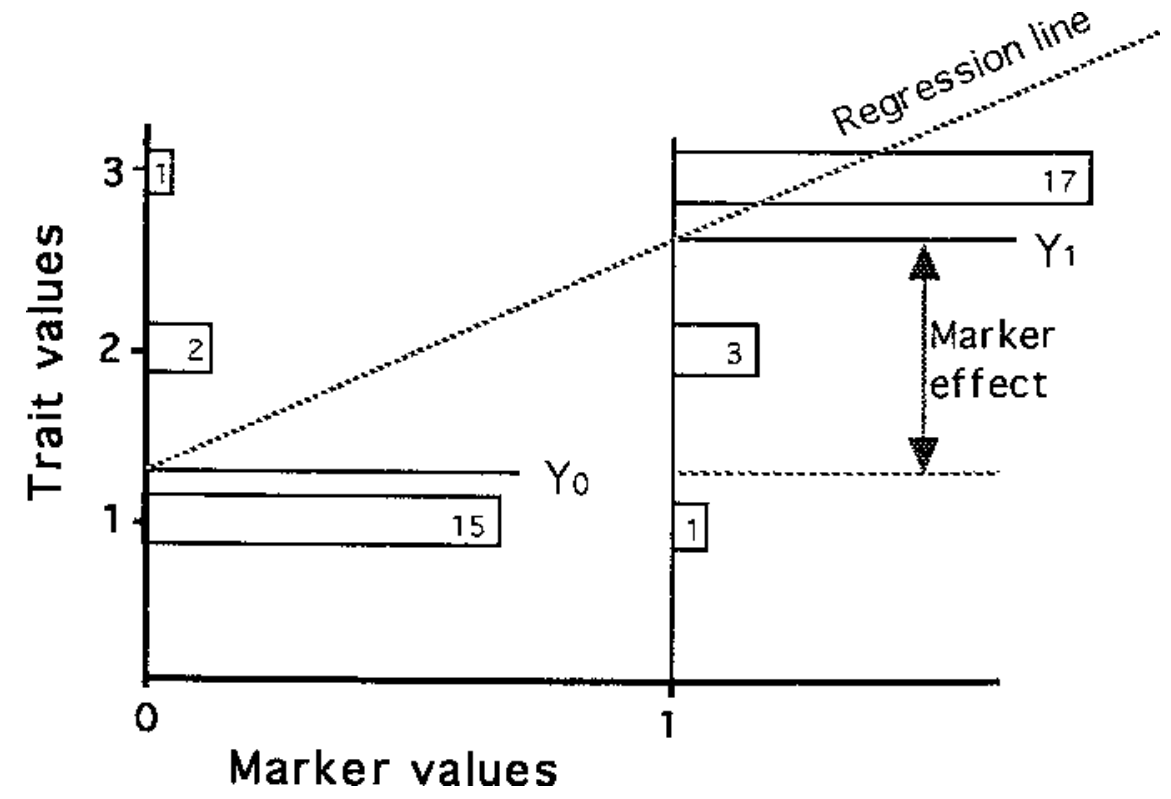

Fig. 2. Schematic example of the definition of the associated effect of a marker on a morphological trait. Trait values were defined under Materials and Methods. Y0 is the average value of the population missing a specific band while $\mathrm{Y} 1$ if the average of the population having the band. Numbers in bars represent number of individuals rated at each trait value.
$1 / 0$ for presence/absence, respectively. Few markers were found to segregate in the progeny but the parents were not polymorphic. This is due to the dominant nature of RAPD markers when genotypes are heterozygous. Primer sequences and parental phenotypes for the 12 markers discussed are listed in Table 1. Marker identification which is used in this manuscript was compiled from a sequential number of the primer and the band number counted from top (large fragments) to bottom (small fragments) in each lane. All statistical analyses (data sorting, means, correlations, multiple stepwise regressions, analysis of variance and mean separation via Duncan multiple range tests) were performed using SAS (SAS Institute, Cary, N.C.) procedures.

\section{Results and Discussion}

Some of the primers tested revealed a high degree of polymorphism between 'Early Muscat' (E) and 'Flame Seedless' (F). More than 70 primers producing polymorphic bands were all tested with 82 individuals of the progeny resulting from the cross between these cultivars (part of the progeny produced nonreliable band patterns with certain primers). More than 400 polymorphic markers were identified. Segregation of two markers is shown in Fig. 1. About 10\% (42) of the markers correlated with just one of the seven traits related to stenospermocarpic seedlessness trait examined. Twelve markers were significantly correlated with more than one component of seedlessness, mainly with the quantitative ones: the mean fresh weight per seed (mg) and the seed fresh weight per berry (mg) (Table 2 ).

For each marker, the progeny was divided into two groups according to the band pattern: 1) band present, and 2) band absent. The average value of the morphological traits in each group is associated and dependent on the number of individuals with the similar phenotype. Thus, the associated effect of each marker for each morphological trait was defined as the regression coefficient

Table 3. Marker effect, significance $(P>\mathrm{F})$, and the ratio of the effect vs. the mean of the progeny (in percent), for the seven subtraits of seedlessness, for three markers: $33.7,39.5,90.7$.

\begin{tabular}{|c|c|c|c|c|c|c|c|}
\hline \multirow[b]{5}{*}{ Marker } & \multicolumn{7}{|c|}{ Morphological trait } \\
\hline & \multicolumn{2}{|c|}{ Fresh wt } & & & & & \\
\hline & \multirow{3}{*}{$\begin{array}{c}\text { Mean one } \\
\text { trace } \\
(\mathrm{mg})\end{array}$} & \multirow{3}{*}{$\begin{array}{c}\text { All traces/ } \\
\text { berry } \\
(\mathrm{mg})\end{array}$} & \multicolumn{2}{|c|}{ Seed size } & \multirow{2}{*}{\multicolumn{3}{|c|}{$\begin{array}{c}\text { Developmental } \\
\text { degree }\end{array}$}} \\
\hline & & & By & & & & \\
\hline & & & perceptibility & Visually & Seedcoat & Endosperm & Embryo \\
\hline \multicolumn{8}{|l|}{33.7} \\
\hline Effect & -17.88 & -54.17 & 0.84 & -0.66 & -0.95 & -0.65 & -0.76 \\
\hline Significance & 0.0002 & 0.0001 & 0.0034 & 0.0174 & 0.001 & 0.0087 & 0.0122 \\
\hline Percent of mean & 71.2 & 81.8 & 44.0 & 20.5 & 47.5 & 28.3 & 35.7 \\
\hline \multicolumn{8}{|l|}{39.5} \\
\hline Effect & -9.46 & -28.30 & 0.52 & -0.73 & -0.52 & -0.62 & -0.75 \\
\hline Significance & 0.0037 & 0.0017 & 0.0491 & 0.0045 & 0.0524 & 0.0087 & 0.0059 \\
\hline Percent of mean & 46.5 & 51.4 & 25.5 & 23.8 & 29.0 & 28.3 & 40.1 \\
\hline \multicolumn{8}{|l|}{90.7} \\
\hline Effect & -16.21 & -43.44 & 0.52 & -0.54 & -0.70 & -0.46 & -0.68 \\
\hline Significance & 0.0001 & 0.0002 & 0.0447 & 0.0320 & 0.0078 & 0.0402 & 0.0112 \\
\hline Percent of mean & 65.8 & 65.4 & 27.5 & 16.8 & 35.3 & 20.2 & 33.2 \\
\hline
\end{tabular}


Table 4. Multiple regression analysis of molecular markers with the seven subtraits of seedlessness. Markers included in the linear model (+), number of markers included, and their correlation coefficients for the seven subtraits of seedlessness.

\begin{tabular}{|c|c|c|c|c|c|c|c|}
\hline \multirow[b]{5}{*}{ Marker } & \multicolumn{7}{|c|}{ Morphological trait } \\
\hline & \multicolumn{2}{|c|}{ Fresh wt } & \multirow{2}{*}{\multicolumn{2}{|c|}{ Seed size }} & \multirow{3}{*}{\multicolumn{3}{|c|}{$\begin{array}{l}\text { Developmental } \\
\text { degree }\end{array}$}} \\
\hline & \multirow{3}{*}{$\begin{array}{c}\text { Mean one } \\
\text { trace } \\
(\mathrm{mg})\end{array}$} & \multirow{3}{*}{$\begin{array}{c}\text { All traces/ } \\
\text { berry } \\
(\mathrm{mg})\end{array}$} & & & & & \\
\hline & & & By & \multirow[b]{2}{*}{ Visually } & & & \\
\hline & & & perceptibility & & Seedcoat & Endosperm & Embryo \\
\hline 27.4 .2 & & + & & & + & & \\
\hline 27.6 .1 & + & + & & & & & \\
\hline 33.7 & + & + & + & + & + & + & + \\
\hline 39.5 & + & + & + & + & & + & + \\
\hline 40.9 & & + & + & & & & + \\
\hline 46.1 .1 & + & & & + & & & \\
\hline 51.5 & + & + & + & + & + & & + \\
\hline 60.1 .3 & & & & & + & & \\
\hline 62.4 & + & & & & + & & \\
\hline 87.8 & + & + & + & + & & & \\
\hline 90.2 & & & & & & + & \\
\hline 90.7 & & & & & & + & \\
\hline Markers & 7 & 7 & 5 & 5 & 5 & 4 & 4 \\
\hline Correlation & 0.675 & 0.779 & 0.684 & 0.570 & 0.526 & 0.424 & 0.492 \\
\hline
\end{tabular}

(for the trait as the dependent variable) (Fig. 2). Since there are only two points of the independent variable ( 0 for band missing and 1 for band present) the difference between the two means (Y1-Y0) is also the slope of the regression line. The larger this difference is, compared to the overall mean of the whole progeny, the higher the effect of the marker is on that specific trait (Table 3). For example, the effect of marker 33.7 on the mean fresh weight of one seed is $-17.88 \mathrm{mg}$. This is the difference between the two groups classified according to band presence and absence. This difference is $71.2 \%$ of the overall mean of the whole progeny for this trait, which indicates a relatively high effect of the marker upon this trait. This marker was found to have significant correlations and effects upon most of the seven components of seedlessness investigated.

It should also be noted that the identification of several markers correlating to individual components of seedlessness supports, on one hand, our suggestion of dividing the trait into components (Striem et al., 1992), and on the other hand it gives more validity to the correlation of each marker by itself with the trait of seedlessness. Several of these markers were also significantly correlated among themselves, with recombination ratios of $17 \%$ to $30 \%$ (unpublished data).

The quantitative nature of the investigated traits suggests that several genes (probably at several loci) are involved in their control and contribute to the evaluated phenotype. Thus, it was not possible for a single marker to be closely linked to seedlessness but it may be possible to find markers for each contributing locus (unless they are all linked, or a major gene is involved). Furthermore, the degree of recombination between a marker and one of the loci involved in seedlessness cannot yet be estimated. We suggest that markers must be identified for each component. This led us to perform multiple linear regression analysis, resulting in higher coefficients, mainly with the quantitative traits, when four to seven markers as independent variables were included in the model (Table 4).

The main use of such markers is as a tool for preselection. As mentioned above, one cannot expect to have one single marker dividing the progeny into seeded vs. seedless offspring. It is more likely that a group of seeded offspring will share similar band patterns for several markers. Furthermore, the opposite band pattern should be found to characterize mainly seedless individuals. To locate such marker combinations, the data of the progeny were sorted by the mean fresh weight per seed. Seedless individuals are located at the top of the list, and seeded ones, at the bottom (Table 5). It was found that the combination of the four markers: $27.4 .2,33.7,62.4,90.7$, which gave a band pattern of $0-0-1-0$ respectively, were found in six seeded individuals. Three different recombinant seeded individuals were found to have $0-1-0-0$ and $0-0-0-0$ band pattern combinations (Table 6). Thus, nine seeded individuals (which are $15.3 \%$ of the whole progeny) could be excluded based on their RAPD marker pattern. In order to exclude more seeded individuals this process was repeated. Elimination of 17 additional offspring (12 seeded, 4 with large traces, and 1 seedless) from the remaining progeny was obtained using additional markers: $39.5,51.5,87.8$ (Table 5). The terms seeded and seedless referred mainly to the size of the seeds and traces evaluated visually, and to perceptibility. The second step of selection included some individuals which could not be analyzed in the first selection due to lack of data with some primers. Furthermore, in the first step, only seeded individuals were excluded, while in the second step some individuals bearing seed traces were excluded as well.

However, the existence of recombinant individuals bearing small seeds, but having rather well developed seedcoats and endosperm, might affect this classification. This could be one of the reasons for individuals not fitting into the described procedure. Thus, seven markers in a two-step selection process successfully excluded 21 out of $29(72 \%)$ seeded individuals, and 4 out of 11 (36\%) individuals with noticeable seed traces. Thus, $44.1 \%$ of the progeny analyzed could be excluded based on their marker phenotype. It should also be noted that the development of additional markers correlating to traits related to seedlessness should improve this analysis. Closer linkage with the genes involved with seedlessness will permit fewer crossing-over events, thus fewer recombinant individuals.

To conclude, 12 molecular genetic markers were identified, correlating to seven subtraits for seedlessness. Highly significant 
Table 5. Partial list (last 41 individuals) of offspring analyzed, sorted by seed fresh weight.

\begin{tabular}{|c|c|c|c|c|c|c|c|c|c|c|}
\hline \multirow{3}{*}{$\begin{array}{l}\text { Vine } \\
\text { no. }\end{array}$} & \multirow{3}{*}{$\begin{array}{c}\text { Seed } \\
\text { fresh wt } \\
(\mathrm{mg})\end{array}$} & \multirow{2}{*}{\multicolumn{3}{|c|}{$\begin{array}{l}\text { Development of } \\
\text { seed components }\end{array}$}} & \multirow{2}{*}{\multicolumn{2}{|c|}{$\begin{array}{l}\text { Evaluation of } \\
\text { seed size }\end{array}$}} & \multicolumn{4}{|c|}{ Molecular marker patterns } \\
\hline & & & & & & & \multicolumn{2}{|c|}{$\begin{array}{c}\text { First selection } \\
27.4 .233 .762 .490 .7\end{array}$} & \multicolumn{2}{|c|}{$\begin{array}{c}\text { Second selection } \\
39.551 .587 .8\end{array}$} \\
\hline & & Seedcoat $^{z}$ & Endosperm $^{\mathrm{y}}$ & Embryo $^{x}$ & Visually $^{\mathrm{w}}$ & Perceptibility $^{\mathrm{v}}$ & To stay & To exclude & To stay & To exclude \\
\hline 188 & 13.6 & 1 & 2 & 1 & $\mathrm{~b}$ & $\mathrm{~S}$ & $1-1-0-1$ & & & $0-0-1$ \\
\hline 130 & 14.3 & 1 & 3 & 2 & $\mathrm{~m}$ & $\mathrm{~S}$ & $1-1-0-1$ & & $1-1-1$ & \\
\hline 119 & 15.2 & 3 & 3 & 3 & $\mathrm{n}$ & $\mathrm{T}$ & $1-1-1-1$ & & & $0-1-1$ \\
\hline 173 & 16.3 & 3 & 3 & 3 & $\mathrm{n}$ & $\mathrm{N}$ & $1-1-0-1$ & & $1-0-1$ & \\
\hline 136 & 16.5 & 1 & 2 & 1 & $\mathrm{~b}$ & $\mathrm{~S}$ & $1-1-0-1$ & & $1-1-1$ & \\
\hline 145 & 17.9 & 1 & 2 & 1 & $\mathrm{~b}$ & $\mathrm{~T}$ & $0-0-1-1$ & & & $0-0-1$ \\
\hline 95 & 19.8 & 1 & 3 & 3 & $\mathrm{~b}$ & $\mathrm{~T}$ & $1-1-0-1$ & & & $0-0-0$ \\
\hline 73 & 20.5 & 3 & 3 & 3 & $\mathrm{n}$ & $\mathrm{N}$ & $0-0-1-1$ & & $1-1-0$ & \\
\hline 114 & 21.1 & 1 & 2 & 2 & $\mathrm{~b}$ & $\mathrm{~T}$ & $1-1-1-1$ & & & $0-1-1$ \\
\hline 185 & 23.4 & 3 & 3 & 3 & $\mathrm{n}$ & $\mathrm{N}$ & $1-1-1-1$ & & & $0-0-0$ \\
\hline 187 & 23.5 & 1 & 2 & 2 & $\mathrm{~b}$ & $\mathrm{~S}$ & $1-1-0-1$ & & $1-0-1$ & \\
\hline 135 & 23.7 & 3 & 3 & 3 & $\mathrm{n}$ & $\mathrm{N}$ & $1-1-1-1$ & & & $0-0-1$ \\
\hline 131 & 24.0 & 1 & 2 & 2 & $\mathrm{~b}$ & $\mathrm{~T}$ & $1-1-0-1$ & & $0-1-0$ & \\
\hline 190 & 25.7 & 1 & 2 & 1 & $\mathrm{~b}$ & $\mathrm{~T}$ & $1-1-0-1$ & & $1-0-1$ & \\
\hline 167 & 26.7 & 2 & 2 & 1 & $\mathrm{~b}$ & $\mathrm{~T}$ & $1-0-0-1$ & & & $0-1-1$ \\
\hline 118 & 27.8 & 1 & 2 & 1 & $\mathrm{~b}$ & $\mathrm{~T}$ & $1-1-0-1$ & & $1-1-1$ & \\
\hline 81 & 29.1 & 3 & 3 & 3 & $\mathrm{n}$ & $\mathrm{S} ?$ & $1-1-1-1$ & & & $0-0-0$ \\
\hline 121 & 29.3 & 3 & 3 & 3 & $\mathrm{n}$ & $\mathrm{N}$ & $1-0-0-1$ & & & $0-0-1$ \\
\hline 107 & 29.7 & 3 & 3 & 3 & $\mathrm{n}$ & $\mathrm{N}$ & $1-0-0-1$ & & $1-1-0$ & \\
\hline 102 & 29.8 & 3 & 3 & 3 & $\mathrm{~b}$ & $\mathrm{~N}$ & $0-0-1-1$ & & $1-0-0$ & \\
\hline 180 & 30.2 & 2 & 2 & 2 & $\mathrm{~b}$ & $\mathrm{~N}$ & $1-1-0-1$ & & $1-1-1$ & \\
\hline 183 & 31.1 & 3 & 2 & 2 & $\mathrm{n}$ & $\mathrm{N}$ & $0-1-1-1$ & & & $0-0-1$ \\
\hline 172 & 32.5 & 2 & 3 & 2 & $\mathrm{n}$ & $\mathrm{T}$ & $1-1-0-1$ & & $1-0-1$ & \\
\hline 189 & 32.8 & 2 & 3 & 3 & $\mathrm{n}$ & $\mathrm{N}$ & $1-1-0-1$ & & & $0-0-1$ \\
\hline 86 & 33.7 & 3 & 3 & 3 & $\mathrm{n}$ & $\mathrm{N}$ & $1-0-1-1$ & & $1-0-1$ & \\
\hline 198 & 34.5 & 3 & 3 & 3 & $\mathrm{n}$ & $\mathrm{N}$ & $1-1-0-0$ & & $1-1-1$ & \\
\hline 76 & 34.2 & 3 & 3 & 3 & $\mathrm{n}$ & $\mathrm{N}$ & $1-1-0-0$ & & & $0-0-1$ \\
\hline 78 & 35.2 & 2 & 3 & 3 & $\mathrm{n}$ & $\mathrm{T}$ & $1-1-0-1$ & & & $0-1-1$ \\
\hline 77 & 39.1 & 2 & 3 & 3 & $\mathrm{n}$ & $\mathrm{N}$ & & $0-1-0-0$ & & $0-0-1$ \\
\hline 84 & 39.3 & 3 & 3 & 3 & $\mathrm{n}$ & $\mathrm{N}$ & 1-1-0-1 & & $1-1-1$ & \\
\hline 196 & 39.8 & 3 & 2 & 3 & $\mathrm{n}$ & $\mathrm{S} ?$ & $1-1-1-\mathrm{NA}^{\mathrm{u}}$ & & & $0-0-0$ \\
\hline 144 & 40.1 & 3 & 3 & 3 & $\mathrm{n}$ & $\mathrm{N}$ & & $0-0-1-0$ & & NA-0-1 \\
\hline 149 & 42.7 & 3 & 3 & 3 & $\mathrm{n}$ & $\mathrm{N}$ & & $0-0-1-0$ & & NA-0-NA \\
\hline 88 & 43.4 & 3 & 3 & 3 & $\mathrm{n}$ & $\mathrm{N}$ & & $0-0-1-0$ & & NA-NA-1 \\
\hline 137 & 46.1 & 3 & 3 & 3 & $\mathrm{n}$ & $\mathrm{N}$ & & $0-0-1-0$ & & NA-0-1 \\
\hline 193 & 46.9 & 3 & 3 & 3 & $\mathrm{n}$ & $\mathrm{N}$ & $1-1-1-1$ & & & $0-0-0$ \\
\hline 158 & 47.0 & 3 & 3 & 3 & $\mathrm{n}$ & $\mathrm{N}$ & & $0-1-0-0$ & & NA-1-1 \\
\hline 115 & 50.6 & 3 & 3 & 3 & $\mathrm{n}$ & $\mathrm{N}$ & & $0-0-1-0$ & & NA-0-1 \\
\hline 116 & 54.2 & 3 & 3 & 3 & $\mathrm{n}$ & $\mathrm{N}$ & & $0-0-1-0$ & & NA-0-1 \\
\hline 160 & 60.3 & 3 & 3 & 3 & $\mathrm{n}$ & $\mathrm{N}$ & & $0-0-0-0$ & & NA- -0 \\
\hline 103 & 65.4 & 3 & 3 & 3 & $\mathrm{n}$ & $\mathrm{N}$ & NA-1-1-0 & & & $0-0-1$ \\
\hline
\end{tabular}

${ }^{\mathrm{z}} 1=$ Soft, to $3=$ hard.

$\mathrm{y}_{1}=$ Partial, to $3=$ full.

${ }^{\mathrm{x}} 1=$ Small, to $3=$ full.

$\mathrm{w}_{\mathrm{S}}=$ Small seed traces, $\mathrm{m}=$ medium seed traces, $\mathrm{b}=$ big seed traces, $\mathrm{n}=$ normal seeds.

${ }^{\mathrm{v}} \mathrm{N}=$ Normal seeds, $\mathrm{T}=$ noticeable seed traces, $\mathrm{S}=$ seedless individual.

uNA $=$ not available.

correlation coefficients and associated effects of the markers upon the traits analyzed were found mainly with the quantitative subtraits. A combination of 4 markers identified 9 seeded offspring in the progeny investigated. Three additional markers identified 21 additional seeded individuals and four individuals with noticeable seed traces. The size of the population could be reduced by $44 \%$ using this marker-assisted-selection process. These results could possi- bly be applied in breeding programs and be used as a tool for preselection. It should first be determined whether these chosen markers are polymorphic among parents. However, markers can be of value even though they are monomorphic among parents when segregating in the progeny. Bulked DNA analysis of the extreme groups can be used in order to estimate the biological effect of the loci involved. 
Table 6. Number of individuals from a population of 82 individuals (and the percentage out of the whole progeny ${ }^{\mathrm{z}}$ ) which were excluded by their band pattern combinations of the markers (27.4.2-33.7-62.4-90.7 and 39.5-51.5-87.8).

\begin{tabular}{|c|c|c|c|c|c|}
\hline \multicolumn{2}{|c|}{ Band pattern of markers } & \multirow{2}{*}{\multicolumn{3}{|c|}{$\begin{array}{l}\text { Individuals } \\
\text { (no.) }\end{array}$}} & \multirow{3}{*}{$\begin{array}{c}\text { Whole } \\
\text { progeny } \\
(\%)\end{array}$} \\
\hline First selection & Second selection & & & & \\
\hline $27.4 .2-33.7-62.4-90.7$ & $39.5-51.5-87.7$ & Seeded & Traces & Seedless & \\
\hline $0-0-1-0$ & & 6 & & & \\
\hline $0-1-0-0$ & & 2 & & & $(9 / 59=) 15.3 \%$ \\
\hline \multirow[t]{4}{*}{$0-0-0-0$} & & 1 & & & \\
\hline & $0-0-1$ & 6 & 1 & 1 & \\
\hline & $0-0-0$ & 4 & 1 & & $(12 / 59=) 28.8 \%$ \\
\hline & $0-1-1$ & 2 & 2 & & \\
\hline Total excluded & & 21 & 4 & 1 & $(21 / 59=) 44.1 \%$ \\
\hline
\end{tabular}

${ }^{\mathrm{z} P r o g e n y: ~} 19$ seedless, 11 noticeable traces, 29 seeded individuals analyzed; 23 individuals could not be analyzed due to nonreliable bandpatterns with these primers.

\section{Literature Cited}

Büscher, N., E. Zyprian, and R. Blaich. 1993. Identification of grapevine cultivars by DNA analyses: Pitfalls of random amplified polymorphic DNA technique using 10mer primers. Vitis 32:187-188.

Gogorcena, Y., S. Arulsekar, A.M. Dandekar, and D.E. Parfitt. 1993. Molecular markers for grape characterization. Vitis 32:183-185.

Gray, D. and C. Meredith. 1992. Grape, p. 229-262. In: F. Hammerschlag and R. Litz (eds.). Biotechnology of perennial fruit crops. C.A.B. Intl., Wallingford.

Jean-Jaques, I., A. Defontaine, and J.N. Hallet. 1993. Characterization of Vitis vinifera cultivars by Random Amplified Polymorphic DNA markers. Vitis 32:189-190.

Kender, W.J. and G. Remaily. 1970. Regulation of sex expression and seed development in grapes with 2-chloroethylphosphonic acid. HortScience 5:491-492.

Ledbetter, C.A. and L. Burgos. 1994: Inheritance of stenospermocarpic seedlessness in Vitis vinifera. J. Hered. 85:157-160.

Ledbetter, C.A. and D.W. Ramming. 1989. Seedlessness in grapes, p. 159-184. In: Jules Janick (ed.). Horticultural reviews. Timber Press, Portland, Ore.

Ledbetter, C.A. and C.B. Shonnard. 1991. Berry and seed characteristics associated with stenospermy in vinifera grapes. J. Hort. Sci. 66(2):247252.

Lodhi, M.A., G.N. Ye, N.F. Weeden, and B.I. Reisch. 1994. A simple and efficient method for DNA extraction from grapevine cultivars and Vitis species. Plant Mol. Biol. Rpt. 12: 6-13.
Pearson, H.M. 1932. Parthenocarpy and seed abortion in Vitis vinifera. Proc. Amer. Soc. Hort. Sci. 29:169-175.

Perl, M., U. Lavi, and P. Spiegel-Roy. 1989. Estimation of seed traces in grape berries by inhibition of luciferase activity. HortScience 24:853.

Ramming D.W., C.A. Ledbetter, and R. Tarailo. 1990. Hybridization of seedless grapes. Vitis (special issue):439-444.

Sandhu, A.S., J.S. Jawanda, and D.K. Uppal. 1984. Inheritance of seed characters in hybrid population of intercultivar crosses of grapes (Vitis vinifera L.). J. Res. Punjab Agr. Univ. 21:39-44.

Spiegel-Roy, P. 1979. Genetics and breeding of almond and grape. Instituto Sperimentale per la Cerealicoltura, Roma. p. 275-293.

Spiegel-Roy, P. I. Baron, and N. Sahar. 1990a. Inheritance of seedlessness in seeded $x$ seedless progeny of Vitis vinifera L. Vitis 29:79-83.

Spiegel-Roy, P., N. Sahar, and I. Baron. 1990b: Seedless X seedless grape progeny: Technique, results and perspectives. Vitis (special issue):432438.

Stout, A.B. 1936. Seedlessness in grapes. New York State Agr. Expt. Sta. (Geneva) Tech. Bul. 238.

Striem, M.J., G. Ben-Hayyim, and P. Spiegel-Roy. 1994. Developing molecular markers for grape breeding, using polymerase chain reaction procedures. Vitis 33:53-54.

Striem, M.J., P. Spiegel-Roy, I. Baron, and N. Sahar. 1992. The degree of development of the seedcoat and the endosperm as separate subtraits of stenospermocarpic seedlessness in grapes. Vitis 31:149-155.

Striem, M.J., P. Spiegel-Roy, G. Ben-Hayyim, J. Beckmann, and D. Gidoni. 1990. Genomic DNA fingerprinting of Vitis vinifera by the use of multi-loci probes. Vitis 29:223-227. 